\title{
Novos Rumos no Tratamento da Bouba
}

\author{
Dr. Waldemir Miranda \\ Dorente livre de Dermatologia da Faculdade de Medicina do Recifie. \\ Chefe de Clinica do Hospital D. Pedro II
}

Dentre os assuntos que a pratica clinica me tem sugerido, em um decenio de atividade hospitalar, fui naturalmente buscar o mais apaixonado ao meu espirito para "Revista de Medicina", dos estudantes da Faculdade de Medicina de São Paulo.

Quero referir-me á bouba ou framboesia tropical, treponemose que, em alguns estados do nordeste e do norte, incide com notavel frequencia, constituindo porisso preocupação sanitaria de grande vulto.

Não seria demasiado acentuar a importancia para a nossa mesologia de uma infeç̧ão cujo campo clinico se extende em face das formas tardias que se pódem apresentar na sua evolução. A existencia da bouba terciaria não parece sofrer contestação. Os tropicalistas brasileiros a tem registrado com expressiva documentação clinica e epidemiologica.

O que dificultou por tantos anos a identificação desses casos foi a sua analogia com a sifilis. Sifilis e bouba se confundem sob multiplos aspectos a começar pelos dados historicos. E de tal maneira se embaralham os fatos que até hoje restam duvidas quanto á epoca do aparecimento desta treponemose em nosso paiz.

Anterior á descoberta do Brasil ou trazida, posteriormente, pelos navios negreiros, o que importa é o estudo sistematico da molestia para orientação cientifica e pratica dos meios de proteção ao individuo doente e á coletividade ameaçada. E, diga-se de passagem, é na terapeutica anti-infectuosa que se encontram as verdadeiras bases da profilaxia da bouba.

Antes, porém, de ser focalisado esse aspecto da questão, algumas noçōes pouco ou erradamente divulgadas exigem um minuto de atenção.

Não têm razão os que insistem em agrupar numa só entidade morbida as duas treponemoses humanas: sifilis e bouba. Não se póde levar a serio a afirmação de que a bouba corresponde á sifilis selvagem, antiga, que nos povos primitivos conserva ainda o seu dermotropismo acentuadamente positivo. Para alguns autores a sifilis atual seria uma modalidade evolutiva creada pela civilisação, sob infuencias diversas: mesologicas, etnicas ou sociais. A sifilis seria a mesma treponemose que se tornou vicero e neurotropica. Embora possa parecer palpitante o debate dessas doutrinas, não cabe fazê-lo nos quadros deste artigo, obrigação, aliás, a que não me sinto preso por já haver tratado do assunto no livro - $A$ bouba no nordeste brasileiro.

Para a quasi unanimidade dos tropicalistas, todavia, bouba e sifilis são mo. lestias distintas. E o que indica a experiencia clinica das zonas em que são frequentes, sem se confundirem. essas duas treponemoses. Ao contrario, dados 
epidemiologicos as separam, aí, suficientemente. Para citar alguns desses elementos diferenciais quero registrar apenas o que se passa para o lado do sistema nervôso. E com isso respondo a uma velha questão:

Póde o treponema pertenue lesar o sistema nervoso? Para argumentar admitam-se as formas nervosas descritas por HARPER na bouba. Mas, si a bouba é capaz de provocar sindromes nervosas, porque o exame do liquido cefalo-raquiano não as surpreenderá no periodo préclinico ou biologico?

Que reações apresentariam, emfim, as meninges no periodo septicemico da bouba?

Em esquema, conforme mostra o quadro apresentado, a punção requiana poz em destaque as seguintes reaçōes, todas ligeiras e quasi sempre isoladas:

$\begin{array}{lr}\text { Hipertensão } & 14,2 \% \\ \text { Hiperleucocitose } & 12,7 \% \\ \text { Hiperalbuminose } & 15,2 \% \\ \text { Hiperglobulinose } & 11,0 \% \\ \text { Wassermann } & 4,3 \% \\ \text { Lange } & 53,8 \%\end{array}$

Em nenhum caso; porém, foram observadas reações positivas completas. Os dois casos de positividade wassermaniana estão prejudicados por acidente de punção (hemorragia), suficiente para explicar a positividade dessa reação pela passagem de reaginas do sangue ao $L$. C. $R$.

A grande percentagem de reação de LANGE positivas, a rigor, poderia ser reduzida pela exclusão de muitos casos em que essa reação foi fraca em intensidade.

Bastaria para isso não considerar como positivos os casos de floculação ligeira, traduzidas em grafico pelo $n .^{\circ} 2$.

Porque, si realmente cabe á reação de LANGE ou de ouro coloidal pela sua sensibilidade a vanguarda das reações coloidais, pouco valem os seus resultados como especificidade.

O que possa afirmar é que as modificações verificadas para o lado do Sistema Nervoso no periodo de erupção framboesiforme não autorisam uma conclusão a favor da existencia de meningite secundaria na infecção pelo tre. ponema de Castelani.

$O$ que se observa é a positividade de certas reações, mas isolaldamente, sem o cortejo das demais alterações biologicas que geralmente se associam entre si nos processos meningiticos bem caracterisados. Reações parciais ou fracas, nesse caso, não satisfazem ao diagnostico. O que fala alto é o conjunto dos exames. E o" "espectro das reaçōes" como bem definiu Eskucken. Por outro lado, nunca surpreendi reações positivas francas em casos de bouba terciaria. $O$ que parece ressaltar dessas pesquizas, feitas em colaboração com o Dr. Alcides Benicio, é a inadaptabilidade do treponema de Castellani á trama meningocerebral.

Não passa, em suma, de germe dermotropico, incapaz de multiplicar-se no tecido nervoso. Dir-se-ia, quando muito, que o treponema lambe as meninges. sem virulencia para ataca-las na intimidade.

Outros aspectos menos especulativos interessam de perto ao Brasil por ser - nosso país o maior foco de bouba na America do Sul.

Que se tem feito, entretanto, para conhecer a extensão do mal?

Quasi nada. A literatura medica nacional, infelizmente, se vem empobrecendo á medida que a bouba se desloca das proximidades dos centros de cultura universitaria para as zonas rurais. Medicos a desconhecem, sanitaristas a desdenham e, ainda mais, já houve quem a considerasse como molestia historica em nosso país, nada mais representando na hora presente. No entanto, assim 
não é. Existem focos disseminados por quasi toda a extensão do Brasil, principalmente no Norte. Nas zonas serranas do Ceará e da Paraiba o mąl assume proporçōes assustadoras. Basta referir, quanto a esses estados, alguns dados informativos. $E_{m} 1933$ os Serviços de Saúde da Paraiba matricularam 3.249 casos de bouba. No Ceará a matricula ascendeu em 1934 a 2.334 casos.

F' curioso assinalar, embora rapidamente, a irregular distribuição geografica da bouba. Ao lado de zonas terrivelmente assoladas, outras escapam á ação do mal.

Qual o motivo dessa caprichosa distribuição geographica?

No nordeste-aparente paradoxo para uma molestia reconhecidamente tropical - são as zonas de clima mais ameno (altitude media - 600 metros) as mais atingidas pela doença. Já não existe, por exemplo, na planicie sertaneja, rareando tambem na faixa litoreana. O que parece explicar, em parte, essa caprichosa repartição da bouba nessas regiões é o fator humidade (a media anual de humidade relativa é de $85 \%$ nas zonas serranas para $61 \%$ no sertão). Outro fator de importancia é a miseria social ao lado do desconhecimento das mais rudimentares noções de asseio e de proteção individual.

Outras causas dadas como predisponentes não têm a importancia que thes foi atribuida. As nossas estastiticas sobre a raça, sexo e idade, mostram a inexistencia de qualquer participação atribuivel a algum desses fatores.

A bouba é realmente a molestia da pobreza, do desasseio e da semi-nudez dos habitantes dos tropicos. Da pobreza que os obriga aos mais rudes misteres, do desasseio que facilita o contagio e da semi-nudez que os expõe aos constantes traumatismos profissionais, portas abertas á infecção.

Passando em revista, sumariamente, outras noções de interesse no estudo da bouba quero destacar dentre muitas as seguintes:

a) sorologia fortemente positiva para todas as reações empregadas no diagnostico da sifilis, não servindo pois esse meio para a diagnose diferencial;

b) mesma observação para as reações alergicas e citologicas (leucocitodiagnostico de Gourn). Ainda outros dados interessantes nos são fornecidos pela experimentação.

1) prova de contagiosidade dos produtos proveniente de lesões boubaticas cutaneas ;

2) prova de virulencia do sangue (periferico e esplenico), dos ganglios e medula ossea dos animais infectados;

3) prova de imunidade retardada, isso em comparação com o que ocorre na sifilis; daí a possibilidade de auto e hetero-infecção nos primeiros tempos da doença, (sete mezes para o macaco, segundo Scholl, e dez para coelho na opinião de Nichols) ;

4) prova de infecção simultanea ou cruzada da bouba e sifilis em um mesmo individuo (para um total de 14 experiencias na sifilis nervosa consegui tres inoculações positivas com aparecimento do cancro boubatico).

Vejamos agora, em linhas gerais, a terapeutica da bouba.

Muita gente se ilude quando afirma que a cura da bouba não exige senão algumas injeções arsenicais. $O$ que se obtem com semelhante terapeutica é apenas a cicatrização das lesões atuais, nunca a cura definitiva da doença.

A sôrologia da bouba isso demonstra cabalmente. $\mathrm{Na}$ maioria dos casos a WASSERMANN ainda se conserva fortemente positivo após a cura dos acidentes secundarios. O silencio clinico que se segue a essas manifestaçóes não indica que se tenha cortado o ciclo evolutivo da molestia no organismo infectado. O drama morbido continua. Cedo ou tarde reviverá o processo morbido - sob os mesmos aspectos das lesões precoces ou sob formas novas proprias do terciarismo boubatico.

Não é desproposito insistir sobre as formas tardias da infecção pelo treponema de CAstrlinis. A bouba não é apenas uma erupção papilomatosa. 
O periodo framboesiforme constitue uma etapa da sua longa evolução. A auença a semelhança da sifilis apresenta tres periodos:

1) acidente de inoculação (bouba mãe ou cancro boubatico).

2) acidentes secundarios generalisados, framboesiformes.

3) acidentes terciarios (forma cutanea geralmente ulcerosa e formas osseas - exostoses e osteites hipertroficas).

Ainda nesse capitulo não vai grande diferença entre a treponemose universal e a tropical. Esta, á semelhança da sua irmã, tambem exige tratamento sistematizado, unico capaz de cortar-lhe a evolução insidiosa. A terapeutica a ser aplicada deve, pois, copiar em linhas gerais a da sifilis, reduzindo, porem, as séries em dose e numero, uma vez que não ha na bouba o perigo das localisações nervosas.

Outro aspecto a encarar cuja importancia crece em se tratando de moJestia mais comum nas populações pobres - é o economico.

A medicação ideal teria de preencher tres condições: ação pronta, eficacia completa e preço reduzido. Para esse objectivo voltam-se no momento todos auneles que se preocupam com o problema da bouba.

De toda parte chegam noticias de tentativas nesse sentido. Varios sucedaneos dos arsenicais, medicação até hoje considerada como unica especifica, não lograram grande exito. Assim falharam os iodetos e o metodo de VAN NitTen de tratamento pelo sulfato de cobre. Só há uma excepção vitoriosa a registrar no fracasso da terapeutica não arsenical da bouba - é o tartaro-vanato de sodio. E' desse produto que me quero ocupar com vagar.

Trata-se realmente de uma medicação eficaz, de ação rapida e que tem sobre os arsenicos a vantagem do preço. Empreguei-a largamente a partir de 1934 com resultados animadores. Ação cicratizante notavel. Cura clinica, em media, com 15 injeções. Estas, dada a habitual tolerancia do doente, poderão ser aplicadas duas ou tres vezes por semana. Com essa tecnica se reduz a hospitalisação dos enfermos a um periodo de 4 a 6 semanas, o que até então só era conseguido com uso da medicação arsenical. Esta, embora mais ativa, nem sempre póde ser usada, apresentando duas desvantagens: uma já referida quanto ao preço elevado, e a outra relativa aos acidentes por ela provocados. E uma medicação que exige maior assistencia da parte do medico, circunstancia que dificulta sua aplicação nos postos anti-boubaticos do interior.

Tenho no arquivo do serviço de dermatologia do Hosp. Pedro II algumas dezenas de observaçōes com o emprego de tartaro-vanadato de sodio, todas corôadas de exito completo. Isso não exclue a necessidade de séries outras para consolidação da cura clinica. E que, como na sifilis, nenhum tratamento põe - doente ao abrígo das formas tardias da infecção. E conveniente aconselhar a todos os beneficiados por esse tratamento a submissão a outras séries, necessarias para a consolidação da cura.

Feito o tratamento de ataque pelos arsenicos ou pelo vanadio, facil é manter o resultado obtido com uso de mais duas séries, sendo uma de bismuto São essas as regras gerais do tratamento da bouba, sujeitas ainda á revisão. Não há, no momento atual, uma pauta de tratamento. Nenhum trabalho ainda de padronisação. $\mathrm{O}$ que fica exposto é apenas uma tentativa nesse sentido. 